\title{
Do people with risky behaviours participate in biomedical cohort studies?
}

\author{
Anne W Taylor*1, Eleonora Dal Grande1, Tiffany Gill11, \\ Catherine R Chittleborough1, David H Wilson'2, Robert J Adams', \\ Janet F Grant ${ }^{1}$, Patrick Phillips ${ }^{4}$, Richard E Ruffin ${ }^{3}$ and the North West \\ Adelaide Health Study Team
}

\begin{abstract}
Address: ${ }^{1}$ Population Research \& Outcome Studies Unit, South Australian Department of Health, Australia, ${ }^{2}$ Health Observatory, Department of Medicine, The University of Adelaide, Australia, ${ }^{3}$ Department of Medicine, The University of Adelaide, South Australia, Australia and ${ }^{4}$ Department of Endocrine Services Queen Elizabeth Hospital, Woodville South Australia, Australia

Email: Anne W Taylor* - anne.taylor@health.sa.gov.au; Eleonora Dal Grande - eleonora.dalgrande@health.sa.gov.au;

Tiffany Gill - tiffany.gill@health.sa.gov.au; Catherine R Chittleborough - catherine.chittleborough@health.sa.gov.au;

David H Wilson - david.wilson@adelaide.edu.au; Robert J Adams - robert.adams@adelaide.edu.au;

Janet F Grant - janet.grant@health.sa.gov.au; Patrick Phillips - patrick.phillips@nwahs.sa.gov.au;

Richard E Ruffin - richard.ruffin@nwahs.sa.gov.au; the North West Adelaide Health Study Team - anne.taylor@health.sa.gov.au

* Corresponding author
\end{abstract}

Published: 23 January 2006

BMC Public Health 2006, 6:II doi:I0.1 I86/I47I-2458-6-II

This article is available from: http://www.biomedcentral.com/I47/-2458/6/I I

(C) 2006 Taylor et al; licensee BioMed Central Ltd.

This is an Open Access article distributed under the terms of the Creative Commons Attribution License (http://creativecommons.org/licenses/by/2.0), which permits unrestricted use, distribution, and reproduction in any medium, provided the original work is properly cited.

\begin{abstract}
Background: Analysis was undertaken on data from randomly selected participants of a biomedical cohort study to assess representativeness. The research hypotheses was that there was no difference in participation and non-participations in terms of health-related indicators (smoking, alcohol use, body mass index, physical activity, blood pressure and cholesterol readings and overall health status) and selected socio-demographics (age, sex, area of residence, education level, marital status and work status).
\end{abstract}

Methods: Randomly selected adults were recruited into a bio-medical representative cohort study based in the north western suburbs of the capital of South Australia - Adealide. Comparison data was obtained from cross-sectional surveys of randomly selected adults in the same age range and in the same region. The cohort participants were 4060 randomly selected adults (18+ years).

Results: There were no major differences between study participants and the comparison population in terms of current smoking status, body mass index, physical activity, overall health status and proportions with current high blood pressure and cholesterol readings. Significantly more people who reported a medium to very high alcohol risk participated in the study. There were some demographic differences with study participants more likely to be in the middle level of household income and education level.

Conclusion: People with risky behaviours participated in this health study in the same proportions as people without these risk factors. 


\section{Background}

Numerous large and important cohort studies have been established overseas [1-6] and in Australia [7-9]. Many of the cohort studies undertaken are based on volunteers or clinical/convenience samples and the follow-up is based on self-report data or record linkages. The establishment of population-based, biomedical, cohort studies using a random sample is less common $[1,2,5,9]$.

Cohort studies are based on the assessment of an individual at several points in time and, by recalling or re-contacting each individual, assessing the process and transition of the individual along the disease and lifecourse continuum $[10,11]$. As argued by Szklo [12] there are numerous, and obvious, advantages if populationbased cohort studies are representative of their defined population. The translations of the data into population estimates over time enable casual relationships to be explored and the ability to separate out the effects of age and maturation, although the main aims are to undertake intra-group comparisons and follow changes over time $[12,13]$. Increasing emphasis is being placed upon these longitudinal data to inform policy makers, health promoters and health planners. With the ageing of the population and the resultant cost pressures placed upon health systems, these data are also being used to make informed predictions about the future use of health services, mortality and morbidity patterns. Cohort studies can provide unique data that provides a more detailed understanding of complex health issues, providing life-course analytical and useful evaluation research opportunities.

Biomedical cohort studies are very costly and logistically difficult to administer $[12,14]$. The benefits and uses of the data are compromised if bias exists. A high initial response rate, a representative initial sample and a low attrition rate are areas where effort needs to be invested to limit selection bias [15-17]. While loss to follow-up is a somewhat expected consequence of the longitudinal nature of all cohort studies, the representativeness of the initial sample, and subsequent ongoing continual assessment of representativeness, are important aspects that warrant investigation [11-13].

This paper investigates the representativeness of an initial cohort to determine if people undertaking risky behaviours were less likely to participate in a major biomedical cohort study and to study the direction and magnitude of any bias found. As argued by Grimes [11], cohort studies should be upfront in identifying and describing the potential effects of any bias and assess similarities and dissimilarities of respondents. This paper aims to identify and describe these biases for a major cohort study established in the western and northern suburbs of Adelaide, the capital of South Australia in which over 4000 ran- domly selected adults have been recruited. The overall aim of this cohort study is to follow the continuum of selected chronic diseases and associated risk factors.

\section{Methods}

The North West Adelaide Health Cohort Study (NWAHCS) recruited between 2000 and 2002 with a total of $n=4060$ adults participating. Randomly selected telephone numbers listed in the relevant postcodes (that equated to the boundaries of the suburbs selected to be included in the study) were drawn from the most current Electronic White Pages. A letter of invitation to participate was sent to these households followed within 10 days by a telephone call from trained health study recruiters. A randomly selected adult within the household (those with the next birthday aged 18 years and older) was asked to participate in the study. At each appointment, the participant was given additional detailed information about the study and asked to sign consent forms for participation in the study. The information given highlighted the longitudinal nature of the study, and participants were informed that they may be invited to participate in health-related sub-studies. Prior to the study commencing, approval for the research was obtained from the North West Adelaide Health Service Ethics of Human Research Committee.

Appointments were made for participants in one of the two hospital-based clinics in the region and participants were sent an information folder that included a questionnaire with questions on chronic disease, alcohol consumption, physical activity levels, quality of life and socio-economic details (including highest education level, marital status, work status, country of birth and household income level). Age, sex, smoking status, height, weight, and ever being told they had high blood pressure or high cholesterol were asked in the recruitment telephone interview. At the clinic a range of assessments were made including taking blood (to test fasting plasma glucose, lipids, HbA1c), skin prick tests to common allergens and spirometry lung function tests.

The overall response rate of the completed telephone interview, self-completed questionnaire and clinic biomedical assessment (including blood sample) was $49.6 \%$ (69\% of those interviewed). This paper assesses data associated with the respondents who completed all aspects of the study. Full details of the methodology have been previously published [18-20].

To examine the representiveness of the NWAHS sample with regard to age, sex, area of residence and socio-economic status, a comparison was made using Australian Bureau of Statistics (ABS) Census figures. Socio-economic status was measured using the Socio Index for Areas, Index of Relative Social Disadvantage (SEIFA IRSD) [21]. 
Table I: Age and sex comparison between 200 I Census and NWAHCS

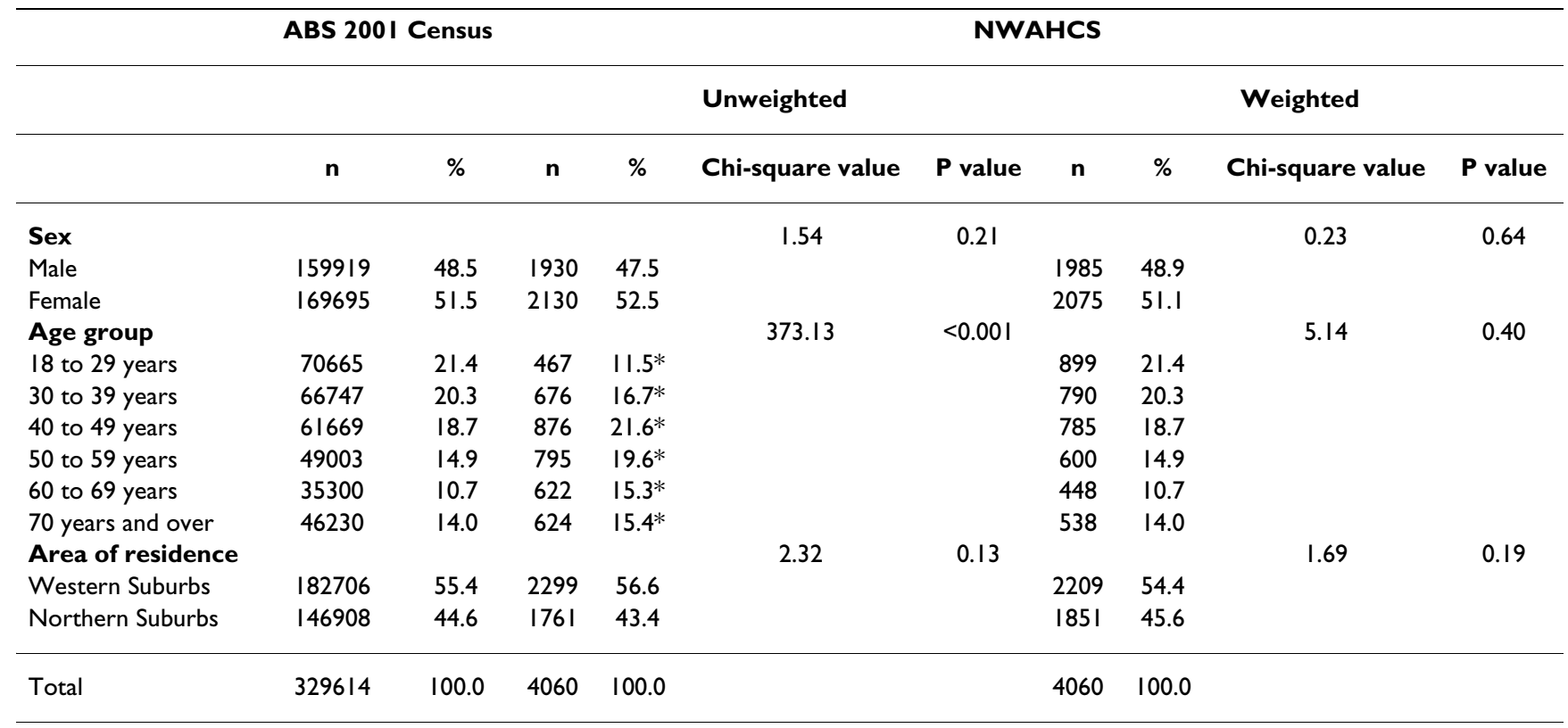

* denotes the category was statistically significantly different compared with ABS Census $200 \mathrm{I}$ using adjusted standardized residuals greater than 2.0 and less than -2.0 ( $\chi^{2}$ test)

To compare the other demographics and social characteristics of the respondents and the population estimates of key health risk factors, a comparison against a populationbased survey, the South Australian Surveillance and Monitoring System (SAMSS), was undertaken. SAMSS is a representative, on-going, population household telephone interview surveillance/survey of the South Australian population based on EWP sampling and has operated each month since July 2002 using a consistent methodology [22]. This involves a random sample of SA households with one person selected at random in each household according to next birthday. Trained health interviewers interview respondents using computer assisted telephone interviewing (CATI) technology and there is no replacement for non-respondents. From July 2002 to June 2004, $\mathrm{n}=2904$ adults in the NW suburbs of Adelaide were interviewed providing a non-replacement response rate of $68.7 \%$. To compare physical activity rates, data from the South Australian Health Monitor were used. Methodology of this CATI survey, operated three times a year, is similar to SAMSS and has been detailed elsewhere [23]. This is a separate comparable survey with a separate sample.

While the questions asked in NWAHCS and SAMSS were identical for age, sex, country of birth, household income, alcohol consumption, height and weight (to calculate body mass index (BMI)), current high blood pressure, current high cholesterol, physical activity and self-reported health status there were slight differences in wording of the question for highest education level, marital status, work status variables and smoking status. Questions on height, weight, blood pressure and cholesterol were only asked of the second half of the respondents although measurements in the clinic were undertaken on all participants.

All analyses were limited to data on respondents aged 18 years and over in the same geographical area to correspond to the NWAHCS sample. Data were weighted by age, sex, region and probalility of selection within the household to the 2001 ABS Census data for SA to provide estimates that were representative of the region's population. The comparison for age and sex using the ABS data used both weighted and un-weighted data. Significance was tested using SPSS V12.0 and EpiInfo Version $6 X^{2}$ tests with a 0.05 level of significance. Adjusted standardized residuals were obtained using the methods of Haberman [24] and were used to test deviations from expected values separately in each cell. Bonferroni corrections were applied for multiple testing.

\section{Results}

Initial analysis using un-weighted data showed that significantly less younger people ( $<40$ years) and more older $(40+$ years) were recruited into the cohort study when compared to Census data. There were no differences by sex or area of residence (Table 1). Table 2 highlights the 
Table 2: SEIFA Index of relative socio-economic disadvantage - comparison between 200 I Census and NWAHCS

\begin{tabular}{|c|c|c|c|c|c|c|}
\hline & \multicolumn{2}{|c|}{ ABS 2001 Census } & \multicolumn{2}{|c|}{ NWAHCS weighted } & \multirow[t]{2}{*}{ Chi-square value } & \multirow[t]{2}{*}{$P$ value } \\
\hline & n & $\%$ & n & $\%$ & & \\
\hline $\begin{array}{l}200 \text { I SEIFA Index of Relative Socio-economic } \\
\text { Disadvantage - quintile }\end{array}$ & & & & & 23.59 & $<0.001$ \\
\hline Lowest quintile & 124457 & 37.8 & 1504 & 37.0 & & \\
\hline 2nd quintile & 65806 & 20.0 & 842 & 20.7 & & \\
\hline $3 r d$ quintile & 88351 & 26.8 & 1174 & 28.9 & & $*$ \\
\hline 4th quintile & 43479 & 13.2 & 445 & 11.0 & & $*$ \\
\hline Highest quintile & 7521 & 2.3 & 94 & 2.3 & & \\
\hline Total & 329614 & 100.0 & 4060 & 100.0 & & \\
\hline
\end{tabular}

Note: Quintiles are based on NW Adelaide population, 18+ years

* denotes the category was statistically significantly different compared with ABS Census $200 \mathrm{I}$ using adjusted standardized residuals greater than 2.0 and less than -2.0 ( $\chi^{2}$ test)

differences by SEIFA quintiles with study participants more likely to be in the $3^{\text {rd }}$ quintile and less likely to be in the $4^{\text {th }}$ quintile of relative socio-economic disadvantage.

Table 3 highlights other demographic comparisons. There were statistically significant differences by education level, with NWAHCS participants more likely to have trade, certificate or diploma qualifications and less likely to have just secondary school qualifications or to have undertaken tertiary study than participants in SAMSS. There were no statistically significant differences by marital status or work status. The NWAHCS had a statistically significant higher proportion of people born in the United Kingdom or Ireland and a lower proportion of Australianborn. There were also differences in the household income level groups with the NWAHCS participants more likely to be in the $\$ 40-80,000$ bracket and less likely to be in the $\$ 80,000+$ bracket.

Table 4 shows the significant differences between the study participants and the comparative population for health risk factors. There was no difference by smoking status, physical activity level, general health status or the proportion with current HBP or current high cholesterol. NWAHCS participants were more likely to be in the intermediate to very high alcohol risk category and less likely to be in the underweight category of BMI.

\section{Conclusion}

This cohort study has offered a unique opportunity to study chronic disease and related risk factors and to define the relationship between lifestyle and health and disease in the Australian population. Cohort studies are one of the most important tools for epidemiological investigation but random sampling cohort studies are often marred by biased samples, low response rates and high loss to follow-up $[12,17]$. Erroneous conclusions can be made if confounding factors are not incorporated in ana- lytical comparisons and models [25]. Bias can be corrected providing confounding was anticipated and confounding factors are appropriately controlled $[26,27]$. This analysis has highlighted the variables that need consideration in future analyses associated with the NWAHCS.

This analysis has shown that in terms of bias associated with risk factors, the cohort participants are not dramatically unlike the community they represent. Their overall self-reported health status is the same, there is the same proportion of current smokers, their overall BMI status (except for underweight) is similar and the same proportion had current high blood pressure or high cholesterol readings. The only major difference was in terms of alcohol consumption with the cohort participants more likely to consume alcohol at an intermediate to high risk level.

In terms of demographic and social characteristics there were no differences by marital status or work status. The un-weighted comparison showed that less younger people and more older persons were recruited into the study. NWAHCS participants were also more likely to be born in UK or Ireland and less likely to be Australian born. These demographic differences could be explained by the fact that NWAHCS participants knew they were being recruited into a bio-medical cohort study with an outlay of personal time and effort required. The clinical meaning associated with the bias associated with this recruitment means we are missing out on the younger persons (expected to be healthier) and gaining more older persons (expected to be unhealthy) although the weighting of the data would counteract some of this bias. The country of birth differences should not affect clinical results as Australian-born and those born in UK/Ireland have similar heritages and social indicators. All future analyses and assumptions will take into account these differences and the fact that the study participants were more likely to 
Table 3: Demographic comparison between NWAHCS and other comparable survey

\begin{tabular}{|c|c|c|c|c|c|c|}
\hline & \multicolumn{2}{|c|}{ NWAHCS } & \multicolumn{2}{|c|}{$\begin{array}{c}\text { SAMSS } \\
\text { (NW Adelaide Study area) }\end{array}$} & \multirow[t]{2}{*}{ Chi-square value } & \multirow[t]{2}{*}{$P$ value } \\
\hline & $\mathbf{n}$ & $\%$ & $\mathbf{n}$ & $\%$ & & \\
\hline Highest education level obtained & \multicolumn{2}{|c|}{ Self completed } & \multicolumn{2}{|c|}{ Telephone } & 287.97 & $<0.001$ \\
\hline Secondary & 1751 & 45.3 & 1742 & 60.1 & & * \\
\hline Trade / Apprenticeship / Certificate / Diploma & $|64|$ & 42.4 & 659 & 22.7 & & * \\
\hline Bachelor degree or higher & 475 & 12.3 & 500 & 17.2 & & $*$ \\
\hline Total & 3867 & 100.0 & 2901 & 100.0 & & \\
\hline Marital status & \multicolumn{2}{|c|}{ Self completed } & \multicolumn{2}{|c|}{ Telephone } & 1.76 & 0.62 \\
\hline Married or living with partner & 2525 & 62.7 & 1830 & 63.1 & & \\
\hline Separated/divorced & 331 & 8.2 & 242 & 8.3 & & \\
\hline Widowed & 232 & 5.8 & 183 & 6.3 & & \\
\hline Never married & 940 & 23.3 & 647 & 22.3 & & \\
\hline Total & 4028 & 100.0 & 2903 & 100.0 & & \\
\hline Work status & \multicolumn{2}{|c|}{ Self completed } & \multicolumn{2}{|c|}{ Telephone } & 6.72 & 0.08 \\
\hline Employed & 2266 & 56.5 & 1633 & 56.2 & & \\
\hline Unemployed & 173 & 4.3 & 128 & 4.4 & & \\
\hline Student & 223 & 5.6 & 124 & 4.3 & & \\
\hline Home duties, retired, other & 1349 & 33.6 & 1019 & 35.1 & & \\
\hline Total & 4011 & 100.0 & 2904 & 100.0 & & \\
\hline Country of birth & \multicolumn{2}{|c|}{ Self completed } & \multicolumn{2}{|c|}{ Telephone } & 8.67 & 0.03 \\
\hline Australia & 2865 & 70.6 & 2114 & 72.8 & & $*$ \\
\hline UK or Ireland & 645 & 15.9 & 389 & 13.4 & & $*$ \\
\hline Europe, The USSR \& the Baltic States & 332 & 8.2 & 249 & 8.6 & & \\
\hline Asia, Other & 217 & 5.4 & 153 & 5.3 & & \\
\hline Total & 4060 & 100.0 & 2904 & 100.0 & & \\
\hline Gross annual household income & \multicolumn{2}{|c|}{ Self completed } & \multicolumn{2}{|c|}{ Telephone } & 16.24 & $<0.001$ \\
\hline Up to $\$ 40,000$ & 1910 & 50.2 & 1239 & 49.4 & & \\
\hline$\$ 40,001-\$ 80,000$ & 1399 & 36.8 & 858 & 34.2 & & $*$ \\
\hline More than $\$ 80,000$ & 492 & 13.0 & 414 & 16.5 & & $*$ \\
\hline Total & 3802 & 100.0 & 2510 & 100.0 & & \\
\hline
\end{tabular}

* denotes the category was statistically significantly different compared with SAMSS using adjusted standardized residuals greater than 2.0 and less than $-2.0\left(\chi^{2}\right.$ test $)$

have middle levels of education and be more likely to be in the middle levels of income.

The strength of this study lies in its representative nature, the large random sample and the high response rate. Although the response rate associated with the complete study involvement, including obtaining blood and other bio-medical measurements, was $49.6 \%$ (69\% of people interviewed by telephone), this is high when compared to other recent, comparable Australian studies. The AusDiab study recorded a response rate of $28 \%$ and a recent pilot for a national Australian biomedical study reported obtaining blood from $23 \%$ of their sample [28]. There is a trend towards lower response rates in all types of population surveys as people protect their privacy, are overwhelmed by marketing telephone calls or mail outs. The additional commitments associated with involvement in a cohort study add to respondent burden. To overcome some of the initial bias afforded to the response rate, the data were weighted by age and sex. The weights reflect unequal sample inclusion probability and compensate for differential non-response. Theoretically the weighted analyses should provide reliable population estimates of health phenomena. 
Table 4: Risk factor comparison between NWAHCS and other comparable survey

\begin{tabular}{|c|c|c|c|c|c|c|}
\hline & \multicolumn{2}{|c|}{ NWAHCS } & \multicolumn{2}{|c|}{$\begin{array}{c}\text { SAMSS } \\
\text { (NW Adelaide Study area) }\end{array}$} & & \multirow[t]{2}{*}{ P value } \\
\hline & $\mathbf{n}$ & $\%$ & $n$ & $\%$ & & \\
\hline Smoking status & \multicolumn{2}{|c|}{ Telephone } & \multicolumn{2}{|c|}{ Telephone } & 0.07 & 0.79 \\
\hline Non or ex-smokers & 3051 & 75.6 & 2202 & 75.9 & & \\
\hline Current smoker & 985 & 24.4 & 700 & 24.1 & & \\
\hline Total & 4036 & 100.0 & 2902 & 100.0 & & \\
\hline Alcohol risk & \multicolumn{2}{|c|}{ Self-complete } & \multicolumn{2}{|c|}{ Telephone } & |5.7 I & $<0.001$ \\
\hline Non drinkers, no risk & 2148 & 53.4 & 1550 & 53.4 & & \\
\hline Low risk & 1630 & 40.5 & 1236 & 42.6 & & \\
\hline Intermediate to very high risk & 244 & 6.1 & 116 & 4.0 & & $*$ \\
\hline Total & 4023 & 100.0 & 2902 & 100.0 & & \\
\hline \multicolumn{7}{|l|}{ BMI } \\
\hline Self-reported & \multicolumn{2}{|c|}{ Telephone } & \multicolumn{2}{|c|}{ Telephone } & 11.00 & 0.01 \\
\hline Underweight $<18.50$ & 14 & 1.0 & 65 & 2.4 & & $*$ \\
\hline Normal 18.50-24.99 & 589 & 43.0 & 1143 & 41.6 & & \\
\hline Overweight $25.00-29.99$ & 505 & 36.8 & 964 & 35.1 & & \\
\hline Obese $30.00+$ & 262 & 19.1 & 573 & 20.9 & & \\
\hline Total & $137 \mid$ & 100.0 & 2746 & 100.0 & & \\
\hline \multicolumn{7}{|l|}{ Current high blood pressure } \\
\hline Self-reported & \multicolumn{2}{|c|}{ Telephone } & \multicolumn{2}{|c|}{ Telephone } & 1.73 & 0.19 \\
\hline No/Don't know & 1284 & 84.2 & 1292 & 85.8 & & \\
\hline Current HBP & 242 & 15.8 & 213 & 14.2 & & \\
\hline Total & 1525 & 100.0 & 1505 & 100.0 & & \\
\hline \multicolumn{7}{|l|}{ Current high cholesterol } \\
\hline Self-reported & \multicolumn{2}{|c|}{ Telephone } & \multicolumn{2}{|c|}{ Telephone } & 3.11 & 0.08 \\
\hline No/Don't know & 1337 & 87.7 & 1350 & 89.7 & & \\
\hline Current & 188 & 12.3 & 155 & 10.3 & & \\
\hline Total & 1525 & 100.0 & 1505 & 100.0 & & \\
\hline \multicolumn{7}{|l|}{ Physical activity } \\
\hline Self-reported & \multicolumn{2}{|c|}{ Self-complete } & \multicolumn{2}{|c|}{ Telephone } & 7.19 & 0.06 \\
\hline Sedentary & 1037 & 28.1 & $|3|$ & 25.3 & & \\
\hline Low exercise level & 1346 & 36.5 & 214 & 41.3 & & \\
\hline Moderate exercise level & 891 & 24.1 & 129 & 24.8 & & \\
\hline \multirow[t]{2}{*}{ High exercise level } & 417 & 11.3 & 45 & 8.6 & & \\
\hline & & & & & 1.70 & 0.19 \\
\hline Sedentary & 1037 & 28.1 & $|3|$ & 25.3 & & \\
\hline Undertakes low to high levels of exercise & 2655 & 71.9 & 387 & 74.7 & & \\
\hline Total & 3691 & 100.0 & 519 & 100.0 & & \\
\hline Self-reported general health status & \multicolumn{2}{|c|}{ Self-complete } & \multicolumn{2}{|c|}{ Telephone } & 0.51 & 0.48 \\
\hline Excellent, very good or good & 3314 & 82.0 & 2363 & 81.4 & & \\
\hline Fair or poor & 725 & 18.0 & 541 & 18.6 & & \\
\hline Total & 4040 & 100.0 & 2904 & 100.0 & & \\
\hline
\end{tabular}

* denotes the category was statistically significantly different compared with SAMSS using adjusted standardized residuals greater than 2.0 and less than $-2.0\left(\chi^{2}\right.$ test $)$ 
To increase the initial response rate the study team implemented a range of well recognized survey techniques. These included consideration of timing of the initial phone contact, timing of phone call and technique (questionnaire length, size), training of recruitment staff, marketing, branding, and a free-call telephone number for inquiries [29]. Early in the recruitment stage, qualitative interviews were conducted with subjects unwilling to participate in the cohort study and the findings incorporated into further recruitment procedures.

Limitations to this analysis include the use of data collected using mixed modes with comparisons based on data collected by telephone and self completion. Bias is known to exist by method of collection, especially in regard to socially desirable responses [30]. An additional weakness of the study was the lack of data on nonresponders. Although some data were collected on people who refused to participate in the biomedical components of the study, a comparison with people unable to be contacted (non-responders to the recruitment telephone call) was not possible due to data limitations on non-responders. The self-report nature of the data collection could also contain an element of bias and therefore be seen as a limitation. The use of biomedical data in addition to the selfreported data in this study (height, weight, and blood pressure and cholesterol measurements) will allow comparisons to be made between reported and measured variables. This analysis is planned.

Many studies have assessed the characteristics of participants and non-participants in population surveys and questionnaire-based cohort studies. Details on, in-depth analysis of, and subsequent publishing of the initial samples for cohort studies that have been initiated in the last decade, in which participants commit to clinic assessments, are few. This study has shown that for this population, people who have risk factors for ill-health were just as likely as others to participate. This is of relevance for researchers interested in establishing a bio-medical cohort study and offers positive encouragement that the huge financial and human resource costs are worthwhile.

\section{Competing interests}

The author(s) declare that they have no competing interests.

\section{Authors' contributions}

AWT conceived of the study, managed the study and drafted the manuscript

EDG participated in the study design performed statistical analysis and helped to draft the manuscript
TKG participated in the study design and management and helped to draft the manuscript

CRC participated in the study design and management and helped to draft the manuscript

DHW conceived of the study, assisted in the management of the study and helped to review the manuscript

RJA assisted with the overall management of the study and helped to review the manuscript

JFG participated in co-ordination of the study and helped to review the manuscript

PJP conceived of the study and helped to review the manuscript

RER conceived of the study and helped to draft the manuscript

All authors read and approved the final manuscript.

\section{Acknowledgements}

We are most grateful to the clinic and recruiting staff for their enormous contribution to the success of the study, and for the generosity of the NWAHS participants in the giving of their time and effort.

The study was initially funded by grants from The University of Adelaide and the South Australian Department of Health.

\section{References}

I. Messerli HF, Mittler BS: Framingham at 50. The Lancet 1998, 352(9133): 1006.

2. Marwick C: NHANES III - Health data relevant for aging nation. JAMA 1997, 277(2): 100-102.

3. Schouten LJ, Goldbohm RA, van den Brandt PA: Height, weight, weight change and ovarian cancer risk in the Netherlands cohort study on diet and cancer. Am J Epidemiol 2003, I 57(5):424-33.

4. Michels KB, Rosner BA, Manson JE, Stampfer MJ, Walker AM, Willett WC, Hennekens $\mathrm{CH}$ : Prospective study of calcium channel blocker use, cardiovascular disease and total mortality among hypertensive women: the Nurses Health Study. Circulation 1998, 97(16): 1540-1548.

5. Bergmann MM, Bussaa $U$, Boeing $H$ : Follow-up procedures in EPIC - Germany - data quality aspects. European Prospective Investigation into Cancer and Nutrition 1999, 43(4):225-34.

6. Smith K, Joshi H: The Millennium Cohort Study. Population Trends 2002, 107:30-4.

7. Giles GG, English DR: The Melbourne Collaborative Cohort Study. Volume 156. IARC Scientific Publications; 2002:69-70.

8. Brown WJ, Bryson L, Byles JE, Dobson AJ, Lee C, Mishra G, Schofield M: Women's Health Australia: recruitment for a national longitudinal cohort study. Women and Health 1998, 28(I):23-40.

9. Knuiman MW, Divitini ML, Olynyk KJ, Cullen DJ, Bartholomew HC: Serum ferritin and cardiovascular disease: a 17 -year followup study in Busselton, Western Australia. Am J of Epidemiology 2003, I58(2): 144-9.

10. Eldredge J: Cohort studies in health sciences librarianship. Journal of Medical Library Association 2002, 90(4):380-392.

II. Grimes DA, Schultz KF: Cohort studies: marching towards outcomes. The Lancet 2002, 359(9303):34I-345.

12. Szklo M: Population-based cohort studies. Epidemiological Reviews 1998, 20(1):8I-90. 
13. Deeg DJH: Attrition in longitudinal population studies: Does it affect the generalizability of the findings? Journal of Clinical Epidemiology 2002, 55:213-215.

14. Samet JM, Munoz A: Perspective: Cohort studies. Epidemiological reviews 1998, 20(I): I35-136.

15. Willett WC, Colditz GA: Approaches for conducting large cohort studies. Epidemiological Reviews 1998, 20(1):91-99.

16. Zaccai JH: How to assess epidemiological studies. Post Graduate Medicine 2003, 80: 140-I47.

17. Doll R: Cohort studies: history of the method. I Prospective cohort studies. Sozial- und Praventivmedizin 200I, 46(2):75-86.

18. Grant JF, Chittleborough CR, Taylor AW, Dal Grande E, Wilson DH, Phillips PJ, Adams RJ, Cheek J, Price K, Gill T, Ruffin RE, the North West Adelaide Health Study Team: The North West Adelaide Health Study: methodology and baseline segmentation of a cohort along a chronic disease continuum. Epidemiologic Perspectives \& Innovations in press.

19. Taylor A, Dal Grande E, Chittleborough C, Cheek J, Wilson D, Phillips $P$, Ruffin R: Key biomedical findings, policy implications and research recommendations. Adelaide: SA Department of Health; 2002.

20. Population Research and Outcome Studies. North West Adelaide Health Study. Brief report 2002-07 [http:// www.dh.sa.gov.au/pehs/PROS/br-nwahs-study02-07.pdf]. [accessed: May 2005 ]

21. Australian Bureau of Statistics. Census of Population and Housing: Socio-economic Indexes for Areas. Information paper. ABS Catalogue no. 2039.01996.

22. The South Australian Monitoring and Surveillance System (SAMSS) Brief Report. 2002 - 20 [http://www.dh.sa.gov.au/ pehs/PROS/br-samss02-20.pdf]. Department of Human Services, South Australia

23. Population Research and Outcome Studies. The Health Monitor Survey methodology. Brief report 2002-12 [http:// www.dh.sa.gov.au/pehs/PROS/br-monitor-method02-12.pdf]. [accessed: May 2005]

24. Haberman SJ: Analyses of qualitative data Volume I. New York, Academic Press; 1978.

25. Davis HTO, Crombie IK: Bias in cohort studies. Hospital Medicine 2000, $61(2): 133-135$

26. Grimes DA, Schulz: Bias and causal associations in observational research. The Lancet 2002, 359(9302):248-252.

27. Fang CT, Shau WY: Epidemiological Research. The Lancet 2002 360:258.

28. Coyne TJ, Findley MG, Ibiebele TI, Forman DW: Overweight and obesity in Australia: an underestimation of the true prevalence. Medical J of Australia 2004, I 80(2):9304.

29. Hunt JR, White E: Retaining and tracking cohort study members. Epidemiological Reviews 1998, 20(1):57-70.

30. De Vaus DE: Surveys in Social Research. 5th edition. Allen \& Unwin. Australia; 2002:130. ISBN I 8650861 I 8

\section{Pre-publication history}

The pre-publication history for this paper can be accessed here:

http://www.biomedcentral.com/1471-2458/6/11/prepub

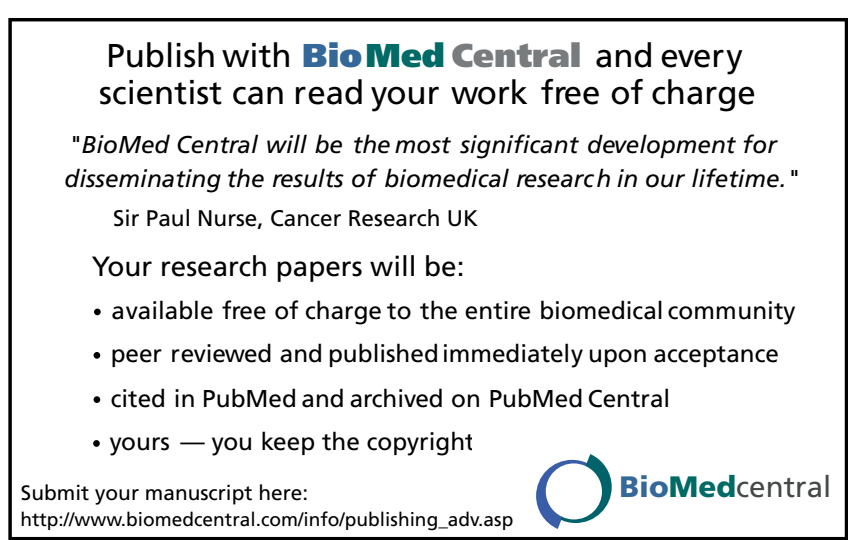

